Article

\title{
Novel Insights into the Configurations of Lead(II)- Benzohydroxamic Acid Coordination Compounds in Aqueous Solution: A Combined Experimental and Computational Study
}

\author{
Jianyong He ${ }^{1}$, Haisheng Han ${ }^{1}$, Chenyang Zhang' ${ }^{1 \& 2, *}$, Yuehua Hu${ }^{1}$, Dandan Yuan ${ }^{3}$, Mengjie Tian', \\ Daixiong Chen ${ }^{2, *}$, Wei Sun ${ }^{1, *}$
}

1 Key Laboratory of Hunan Province for Clean and Efficient Utilization of Strategic Calcium-containing Mineral Resources, School of Minerals Processing and Bioengineering, Central South University, Changsha, Hunan 410083, China.;

2 Key Laboratory of Hunan Province for Comprehensive Utilization of Complex Copper-Lead Zinc Associated Metal Resources , Hunan Research Institute for Nonferrous Metals, Changsha 410100 , China

3 Institute of theoretical and computational chemistry, Nanjing University, Nanjing, Jiangsu 210023, China; yddmjm@qq.com

* Correspondence: zhangchenyang@csu.edu.cn (Chenyang Zhang); sunmenghu@csu.edu.cn (Wei Sun); Tel:+8673188830482; chendaixiong888@163.com (Daixiong Chen); Tel: +8673185239033.

Jianyong He and Haisheng Han contribute equally to this work

\begin{abstract}
Novel collector lead(II)-benzohydroxamic acid ( $\mathrm{Pb}(\mathrm{II})-\mathrm{BHA})$ complexes in aqueous solution were characterized by using experimental approaches, including Ultraviolet-visible (UVVis) spectroscopy and electrospray ionization-mass spectrometry (ESI-MS), as well as first-principle density functional theory (DFT) calculations with consideration for solvation effects. The Job plot delineated that a single coordinated $\mathrm{Pb}(\mathrm{BHA})^{+}$should be formed first, and the higher coordination number complexes can be formed subsequently. Moreover, the $\mathrm{Pb}$ (II)-BHA species can aggregate with each other to form complicated structures, such as $\mathrm{Pb}(\mathrm{BHA})_{2}$ or highly complicated complexes. ESI-MS results validated the existence of $\mathrm{Pb}-(\mathrm{BHA})_{\mathrm{n}=1,2}$ under different solution $\mathrm{pH}$ values. Further, the first-principles calculations suggested that $\mathrm{Pb}(\mathrm{BHA})^{+}$should be the most stable structure, and the $\mathrm{Pb}$ atom in $\mathrm{Pb}(\mathrm{BHA})^{+}$will act as an active site to attack nucleophiles. These findings are meaningful to further illustrate the adsorption mechanism of $\mathrm{Pb}(\mathrm{II})-\mathrm{BHA}$ complexes in mineral processing.
\end{abstract}

Keywords: $\mathrm{Pb}$ (II)-BHA; lead chemistry; metal-organic collectors; DFT calculation; surface activation

\section{Introduction}

Metal-organic coordination complexes have been widely used in the materials, chemistry. Recently, their promising applications in mining have attracted research attention [1-8]. For instance, lead(II)-benzohydroxamic acid ( $\mathrm{Pb}$ (II)-BHA) complexes are effective collectors in the beneficiation of oxide minerals, including tungsten minerals, cassiterite, and rutile $[9,10]$. Given the excellent selectivity and good collecting ability of $\mathrm{Pb}(\mathrm{II})-\mathrm{BHA}$, the scheelite flotation process could be simplified remarkably without the addition of sodium silicate, overcoming the shortage of heating in the routine flotation of scheelite [9-11].The beneficiation of scheelite is currently one of the most challenging problems worldwide in the field of mineral processing. Conventionally, separating scheelite from calcium bearing minerals, such as fluorite and calcite, by using anionic collectors (especially for fatty acid) is difficult due to their highly similar properties in calcium-bearing surfaces $[12,13]$. Fortunately, our group first introduced the $\mathrm{Pb}$ complexes of benzohydroxamic acid $(\mathrm{Pb}(\mathrm{II})-$ 
BHA complexes) to effectively separate scheelite from calcium-bearing gangues by properly regulating the $\mathrm{Pb} / \mathrm{BHA}$ ratio and $\mathrm{pH}[9,11]$. Furthermore, as displayed in Figure 1(a), the novel flotation scheme (i in Figure $1[\mathrm{~b}]$ ), with $\mathrm{Pb}(\mathrm{II})$-BHA complexes used as the collector, has shown better performance than the traditional activation flotation scheme (ii in Figure 1 (b)), which first added $\mathrm{Pb}(\mathrm{II})$ as the activator and subsequently added BHA as the collector [10,14-23]. The effective microstructures of $\mathrm{Pb}$ (II)-BHA complexes in the solution, however, as well as their interaction mechanisms with oxide minerals remain unclear.

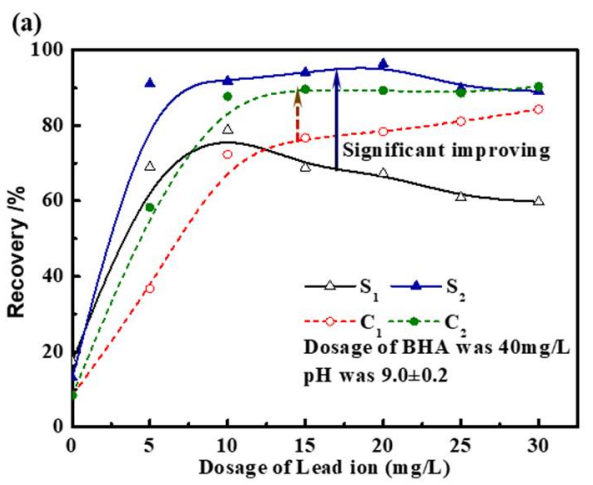

(b)

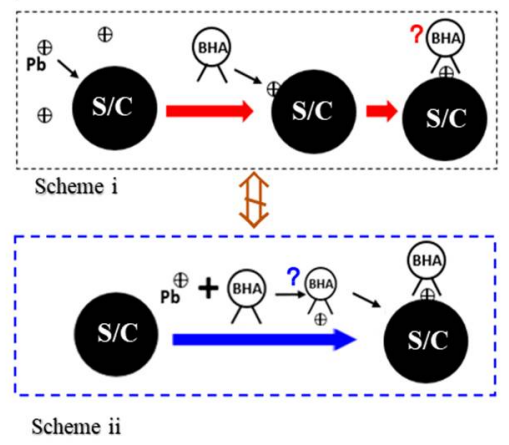

Figure 1. (a) The flotation recovery of scheelite (S) [9] and cassiterite (C) [24] as a function of dosage of $\mathrm{Pb}(\mathrm{II})$ ion (1/2 in (a) represents the flotation scheme in i and ii in (b)); (b) Two flotation schemes.

The hydroxamic acid group $(-\mathrm{CO}-\mathrm{NH}-\mathrm{OH})$ is the functional group of the BHA [25-27]. The functional group has relatively different properties that remain poorly characterized; in fact, a reliable assignment of the correct structure is challenging because the several possible conformations strongly depend on concentration, temperature, and the nature of the solvent [28]. The hydroxamate collectors, such as benzohydroxamic acid (BHA), naphthenic hydroxamate, and amide hydroxamate, have been useful as highly selective flotation collectors in recent years. The role to function as collectors in mineral flotation has been documented by Lynch et al. [29] The chelate between hydroxamic acids and the metal ion, however, has remained poorly investigated. Currently, firstprinciple calculations based on density functional theory (DFT) and some advanced experimental technologies are used to obtain more information on the molecular structure of BHA [30]. Wander et al.'s benchmarking calculations indicate that the DFT calculation can achieve near chemical accuracy of hydrolysis constants for metal ions in most cases [31]. Nuclear magnetic resonance and DFT calculations performed by Garcia et al. show that the adopted BHA conformation of BHA aqueous solution is a closed $\mathrm{Z}$ (cis) configuration in aqueous solution [32]. Both $\mathrm{Z}$ (cis) and $\mathrm{E}$ (trans) conformations in Scheme 1 regularly co-exist in solvent. The concentration and environmental factors determine the ratio of $\mathrm{Z}$ type to $\mathrm{E}$ type conformations to some extent, and potential barriers are present among different conformations [33,34].

Scheme 1. BHA conformers

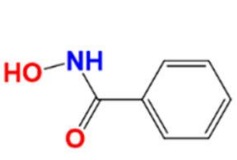

Z-amide

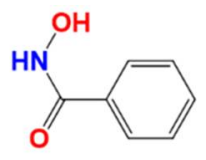

E-amide

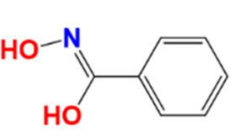

Z-imide

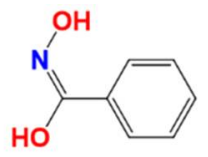

E-imide

BHA can chelate with metal ions, such as copper(II) cadmium(II), cobalt(II), nickel(II), manganese(II), lead(II), zinc(II), aluminum(III), iron(III), and bismuth(III), thus taking on diverse chelate structures [26,35]. Very few heavy metal ion complexes of BHA chelates have been extensively investigated for their special uses, such as the bismuth(III) complex that has activity against Helicobacter pylori; however, reports about the novel $\mathrm{Pb}(\mathrm{II})$ - $\mathrm{BHA}$ complexes are also few. 
Understanding the microstructures of $\mathrm{Pb}$ (II)-BHA complexes is essential to improve the technique working in flotation practice and fundamental field of lead chemistry [36,37].

This current study aims to investigate configurations of $\mathrm{Pb}(\mathrm{II})-\mathrm{BHA}$ coordination complexes in aqueous solution. Accordingly, UV-Vis spectroscopy and electrospray ionization mass spectrometry (ESI-MS) were performed to characterize the configuration of $\mathrm{Pb}$ (II)-BHA complexes. Furthermore, first-principle DFT calculations were performed to understand the constituents and properties of $\mathrm{Pb}$ (II)-BHA complexes at the molecular level. The frontier molecular orbital [38] and natural atomic orbitals (NAOs) [39] were used to describe the reactivity of the studied $\mathrm{Pb}$ (II)-BHA complex. This work has shed new light on effective microstructures of $\mathrm{Pb}$ (II)-BHA coordination complexes for mineral flotation.

\section{Methodology}

\subsection{Experimental details}

\subsubsection{Materials}

Analytical grade BHA and lead nitrate were purchased from Tokyo Chemical Industry Co., Ltd. in Japan. The $\mathrm{pH}$ value was adjusted with chemically pure sodium hydrate or hydrochloric acid stock solutions. The 18.2 M $\Omega$ pure water produced by Arium Mini Plus (Sartorius Weighing Technology, Germany) was used in this work.

\subsubsection{UV-Vis tests}

The UV-vis spectrum of the $\mathrm{Pb}(\mathrm{II})$-hydroxide system has been investigated elsewhere[40]. Here we will not assign the characteristic peaks of the $\mathrm{Pb}$ (II)-BHA complex. The Job plot[41], proposed by Job, provides qualitative and quantitative insight into the stoichiometry with the underlying association of ligand- and solvent-dependent reaction rates. The Job plot was used to track the full reaction path. Moreover, we changed the guest and host solution to comprehensively understand the stoichiometry of the product. In this work, the concentration of the $\mathrm{Pb}$ (II)-BHA complex, as determined by integration of the intensity of specific wavenumber, was plotted against the mole fraction $\mathrm{X}_{\mathrm{A}}$ (the guest solution is $\mathrm{BHA}$ solution) and $\mathrm{X}_{\mathrm{B}}$ (the guest solution is $\mathrm{Pb}(\mathrm{II})$ ion solution). $\mathrm{A}$ Shimadzu UV2600/2700 Ultraviolet spectrophotometer was used to obtain the UV-Vis spectra at a fixed concentration of $\mathrm{Pb}$ (II) ion at $0.1 \mathrm{mM}$ using the equimolar continuous change method and molar ratio method.

\subsubsection{ESI-MS tests}

ESI-MS spectra were collected in positive ion mode with a Bruker Q-TOF Qualification Standard Kit, using solutions of the $0.1 \mathrm{mM} / \mathrm{L}$ mixture of lead nitrate:BHA. ESI-MS spectra were used to obtain the proof of coordinated compounds of $\mathrm{Pb}(\mathrm{II})$-BHA complexes at the molar ratio of 1:1 (at the natural $\mathrm{pH}$ 4.4) and 1:2 (at $\mathrm{pH} 13.0$ ). The $\mathrm{pH}$ was selected according to a report that high $\mathrm{pH}$ can result in increased complications in solution species [10].

\subsection{Computational methods}

All calculations were performed with the Gaussian 09 (version D.01) quantum chemistry package, based on the B3LYP method: a three-parameter hybrid functional by replacing a certain amount of the PW91 generalized gradient approximation (GGA) correlation functional with the LYP GGA correlation functional [42-44]. The implicit solvation effects were considered using the polarized continuum models (PCM) in the calculation [45]. On the other hand, the water molecules in the first hydration of $\mathrm{Pb}(\mathrm{II})$-BHA complex were also considered with the explicit solvation model. The augcc-pVDZ basis set was employed as all-electron basis set in all types of calculation on the light atoms $\mathrm{H}, \mathrm{C}, \mathrm{N}$, and $\mathrm{O}$, except for the $\mathrm{Pb}$ atom in $\mathrm{Pb}$ (II)-BHA complex systems. The aug-cc-pVDZ-PP basis set with a relativistic pseudopotential was used for the $\mathrm{Pb}$ atom. The basis set, obtained from EMSL 
Basis Set Exchange web site, has already been verified as producing acceptable thermodynamic information of hydrated $\mathrm{Pb}(\mathrm{II})$ ions [46-48]. The Los Alamos effective core potential double- $\xi$ (LanL2Dz) was used for the primary geometry optimization of modeled benzohydroxamic acid and its $\mathrm{Pb}$ (II) complex in ionic form. LanL2Dz replaced 78 core electrons with relativistic effective core potential (RECP) [49]; therefore, only two valence electrons of $\mathrm{Pb}(\mathrm{II})$ ions were described [50]. To refine the structure and calculate the molecular orbitals, we further used the larger aug-cc-pVDZ basis set for the light atoms, such as hydrogen, oxygen, nitrogen, and carbon, and we used the augcc-pVDZ-PP with RECP of the inner 60 electrons for $\mathrm{Pb}$ (II) ions to calculate the frequency [51]. The default convergence parameters (with maximum force within $4.5 \times 10^{-4}$, force RMS within $1.8 \times 10^{-3}$ ) in the Gaussian 09 software were retained to optimize the structure. All calculations were successfully converged, without virtual frequencies in the vibration analysis.

There are three protonation sites in the BHA molecule. The carbonyl oxygen site is found to be the preferred site for protonation by Arora et al.[52] in aqueous solution. In the building of BHA anion models [53], the proton at the carbonyl oxygen was removed according to the preferred deprotonation site reported by Begoña et al. and [32]. The $\mathrm{Pb}$ (II) ion was set as the metal center ion which would be the coordination center of the bidentate BHA anions. The envisaged conformations were ligated by two, three and four BHA anions. Thermodynamic values for Gibbs free energy [54] were obtained using the PCM with the context:

$$
\Delta G_{r}=\sum G_{\text {prod }}-\sum G_{\text {react }}
$$

where $G_{\text {prod }}$ and $G_{\text {react }}$ are the free energy or the products and the reactants included in the reaction, respectively.

Gauss View was used as a visualization tool in this paper. In addition, all calculations including the mapped molecular orbitals in this work were performed at the theory level of PCM -B3LYP/augcc-pVDZ on light atoms (C, H, O, N) and PCM -B3LYP/aug-cc-pVDZ-PP on Pb atoms [55]. Molecular orbital contours for the highest occupied molecular orbital (HOMO) and the lowest unoccupied molecular orbital (LUMO) of the cluster model were computed at the same theoretical level. The contributions of $\mathrm{Pb}$ atom to the frontier molecular orbitals were calculated with a multifunctional wavefunction analyzer Multiwfn [56] based on the NAOs.

\section{Results and discussion}

\subsection{Experimental}

3.1.1. UV-vis results 

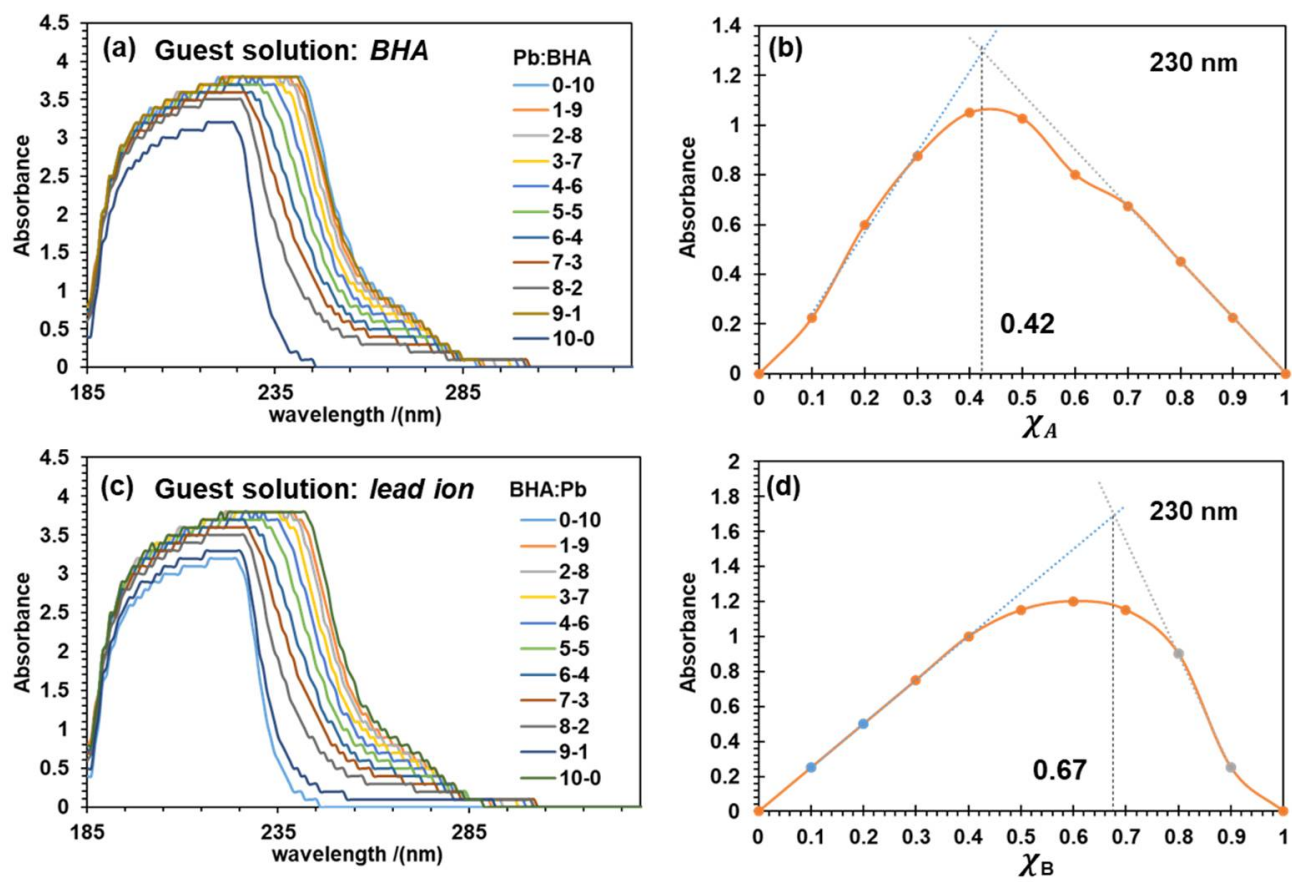

Figure 2. (a) and (b) are the UV-Vis absorbance spectra spanning the wavelength from $185 \mathrm{~nm}$ to 325 $\mathrm{nm}$ for the different dosing strategies; (b) and (d) are the corresponding Job plots at $230 \mathrm{~nm}$ of (a) and (b), respectively. $\mathrm{X}_{\mathrm{A}}$ and $\mathrm{X}_{\mathrm{B}}$ are the mole fractions of $\mathrm{Pb}(\mathrm{II})$ ions and $\mathrm{BHA}$ according to dosing strategies 1 and 2, respectively. All stock solutions are prepared at $1 \mathrm{mM} / \mathrm{L}$ concentration.

Because of the superposition of UV-Vis absorbance peaks of the products and the reactants, carefully processing the collected UV-Vis data is essential. Initially, the first and the last points were fixed at zero absorbance because the complexity of the product might be relatively different when one component is in excess, and the further fitting procedures would exclude the two points [57]. The starting second point and the last second point were connected to form a background. After deducing the background absorbance, the Job plots were plotted, as shown in Figures 2(b) and 2(d). Here, Job plots were fitted using the method of initial tangents using experimental data close to the beginning points (the first and last points were not included due to the formation of hydrated $\mathrm{Pb}$ complexes and the solvation of $\mathrm{BHA}$ ) [58]. As illustrated in Figure 2, $\mathrm{X}_{\mathrm{A}}$ and $\mathrm{X}_{\mathrm{B}}$ were the mole fractions of $\mathrm{Pb}$ (II) ions and BHA according to dosing method 1 and 2, respectively. The wavelength at $230 \mathrm{~nm}$ represents the significant changes in the solution components. The same trends can also be obtained by using other wavelengths between 230 and $240 \mathrm{~nm}$ (Figure 3).

Figures 2(a) and 2(c) show that the increasing dosage of $\mathrm{Pb}$ (II) ions and BHA has strengthened and extended the absorbance peaks. Job plots have been obtained from the newly mixed $\mathrm{Pb}(\mathrm{II})-\mathrm{BHA}$ mixture, with the collected characteristic absorbance peaks of UV-Vis spectra in aqueous solution having both dosing methods. The absorbance peak at $230 \mathrm{~nm}$ has been plotted with respect to the range of the molar ratios of $\mathrm{Pb}$ (II):BHA from 1:9 to 9:1. The obtained Job plots show that the stoichiometry of the complexes for the first one with BHA as a guest solution is $X_{\mathrm{A}}=0.42$ (Figure 2(b)), which supports a stoichiometry of $\mathrm{Pb}(\mathrm{II})$ : $\mathrm{BHA}$ between 1:1 to 1:2. Meanwhile, the reversing dosing method with the $\mathrm{Pb}(\mathrm{II})$ ion solution as the guest solution obtained $\mathrm{X}_{\mathrm{B}}=0.67$ (Figure 2(d)), clearly indicating that a stoichiometry of $1: 2$ corresponds to the structure of $\mathrm{Pb}(\mathrm{BHA})_{2}$. These results support the formation of $\mathrm{Pb}(\mathrm{BHA})_{2}$ complex when excessive $\mathrm{BHA}$ solution is added.

At the natural $\mathrm{pH}$ value of 4.4, the main components of $\mathrm{Pb}^{2+}$ solution are the $\mathrm{Pb}^{2+}$ cations [40]; as for the BHA solution, the mean components are $\mathrm{BHA}^{-}$anions [59]. Hence, both $\mathrm{Pb}^{2+}$ and $\mathrm{BHA}^{-}$should be the main reactants involved in the coordination reaction. In addition, The stability constants obtained in our previous work [10] for the Pb-BHA complexes are 9.14 \pm 0.05 ([Pb][BHA $]^{+}$) and $12.63 \pm 0.01\left([\mathrm{~Pb}][\mathrm{BHA}]_{2}\right)$. Apparently, these experimental results support the existence of $\mathrm{Pb}(\mathrm{BHA})^{+}$ 
and $\mathrm{Pb}(\mathrm{BHA}) 2$. Considering the order that we prepared the mixture for the UV-Vis tests can influence the reaction paths, the accepted potential reaction mechanism might be described as follows:

$$
\begin{gathered}
B H A^{-}+P b^{2+} \rightarrow P b(B H A)^{+} \stackrel{B H A}{\rightarrow} P b(B H A)_{2} \\
2 B H A^{-}+P^{2+} \rightarrow P b(B H A)_{2}
\end{gathered}
$$

where Equation (2) can be explained as the stepwise formation of the single coordinated $\mathrm{Pb}(\mathrm{BHA})^{+}$complex, when a small quantity of $\mathrm{BHA}^{-}$solution is used as a guest specie, and Equation (3) is ideal for interpreting the formation of $\mathrm{Pb}(\mathrm{BHA})_{2}$, when $\mathrm{Pb}(\mathrm{II})$ solution is used as a guest specie. The water molecules and other ions are not included to better identify the highest coordination number of BHA with $\mathrm{Pb}(\mathrm{II})$.

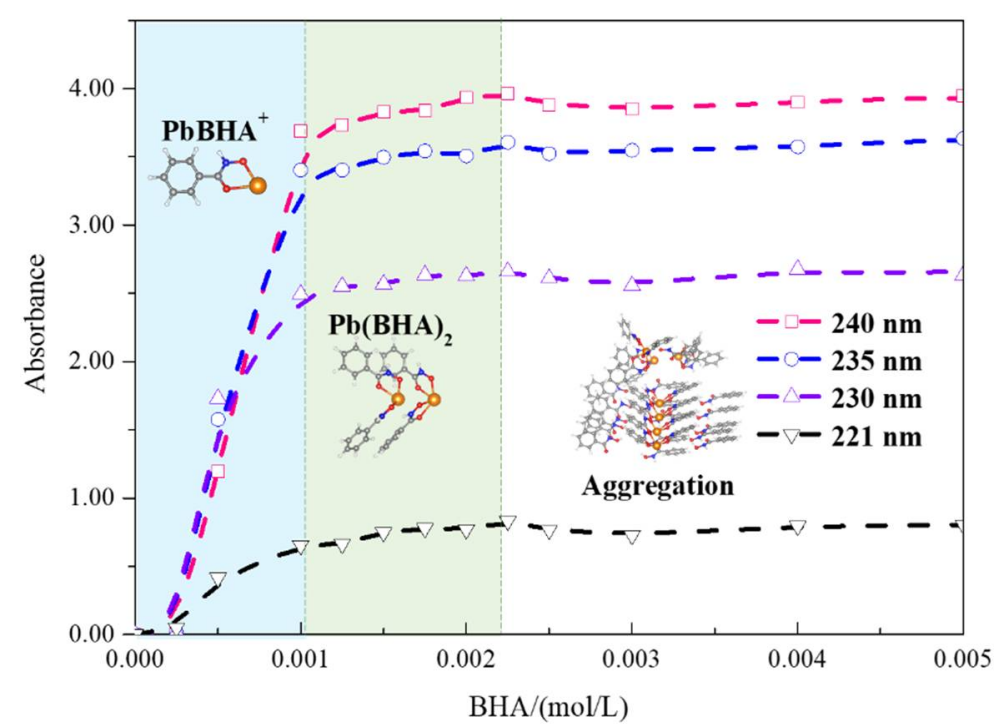

Figure 3. $\mathrm{UV}-\mathrm{V}$ is absorbance changes of $1 \mathrm{mM} / \mathrm{L} \mathrm{Pb}(\mathrm{II})$ ion solution with respect to the continuous addition of BHA (at wavelengths of 221, 230, 235, and $240 \mathrm{~nm}$ ), based on the continuous concentration change method. Spheres for atoms $\mathrm{Pb}, \mathrm{C}, \mathrm{H}, \mathrm{O}$, and $\mathrm{N}$ in the inset are colored in orange, grey, white, red, and blue, respectively.

Figure 3 shows the continued UV-Vis test results at the characteristic peaks of 221, 230, 235, and $240 \mathrm{~nm}$ that can explain the mechanism of forming high coordination complexes. These drawn curves show a consistent trend. For a clear illustration, we have divided these curves into three stages. At the beginning stage, the absorbance increases rapidly. At the end of the rising stage at $1 \mathrm{mM} / \mathrm{L}$ of BHA, a 1:1 (v:v) $\mathrm{Pb}(\mathrm{II})-\mathrm{BHA}$ complex is formed, which is consistent with both the obtained result of the $\mathrm{Pb}(\mathrm{BHA})^{+}$complex in the Job plots and the computational section. Afterward, the curves shows a slow rising stage region with a small slope from $1 \mathrm{mM} / \mathrm{L}$ to $2.5 \mathrm{mM} / \mathrm{L}$. The fluctuation of these collected data suggests that the component in the solution should be intricate. Interestingly, these trends end with the same proportion of $\mathrm{Pb}: \mathrm{BHA}=1: 2.5$, at which the $\mathrm{Pb}(\mathrm{BHA})_{2}$ complex can exist as indicated by the Job plots. When increasing the BHA concentration, these curves adopt a horizontal line-like region of the similar absorbance intensity to pure BHA solution.

The three stages in the curve can be seen as the stepwise formation of high coordination complexes, as interpreted by Equation (2). Note that the higher coordination components with more than 2 BHA as ligands are not sufficiently supported by the Job plots. Better experimental evidence has been collected from the electrospray ionization-mass spectrometry (ESI-MS) spectra. 


\subsubsection{ESI-MS spectra}
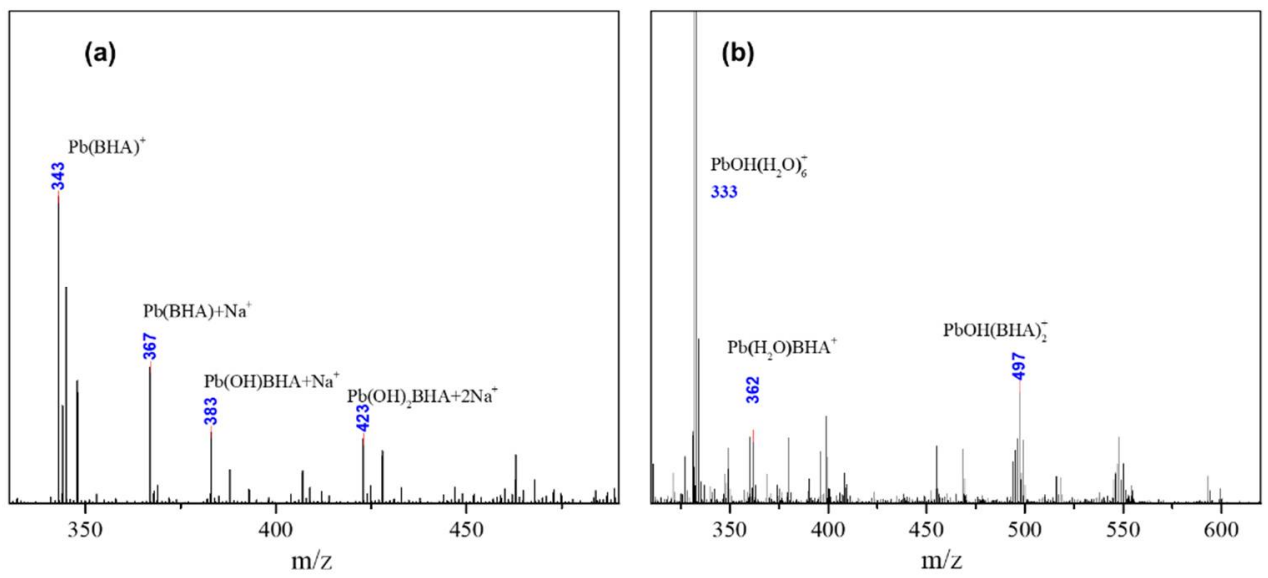

Figure 4. ESI-MS spectra of the mixture of (a) Pb:BHA molar ratio of 1:1 at a pH value of 4.4 and (b) $\mathrm{Pb}: \mathrm{BHA}$ molar ratio of 1:2 at the natural $\mathrm{pH}$ of 13.0. (Solution concentrations are $1 \mathrm{mM} / \mathrm{L}$.).

To identify possible $\mathrm{Pb}$ (II)-BHA complexes formed in the solution, the collected ESI-MS data of reaction mixtures of lead nitrate and BHA with water as the solvent at the positive mode are shown in Figure 4. Figure 4(a) shows that when the solution $\mathrm{pH}$ is approximately 13.0 in the mixture, the main product is the single coordination complex $\mathrm{Pb}(\mathrm{BHA})^{+}$with $\mathrm{m} / \mathrm{z}$ values of 343 . Figure $5(\mathrm{~b})$ shows that $\mathrm{Pb}$ (II)-BHA complex at the molar ratio of 1:2 can produce $\mathrm{m} / \mathrm{z}$ values of 362 and 497 responding to the $\left.\left[\mathrm{Pb}_{2} \mathrm{H}_{2} \mathrm{O}\right) \mathrm{BHA}\right]^{+}$and $\left[\mathrm{PbOH}(\mathrm{BHA})_{2}\right]^{+}$in aqueous solution, respectively. The later $\left[\mathrm{PbOH}(\mathrm{BHA})_{2}\right]^{+}$configuration is quite abnormal, in which lead ion possesses a positive tetravalence. The reason for this is still unclear. However, this does not affect the following discussions and conclusions. Proof of the single coordinated $\mathrm{Pb}$ (II) complex and double coordinated complex with $\mathrm{BHA}$ as ligands is provided, indicating that the $\mathrm{Pb}(\mathrm{BHA})^{+}, \mathrm{Pb}(\mathrm{BHA})_{2}$, and the possible high coordination complexes are closely related to the $\mathrm{pH}$ value. This finding is consistent with the result obtained from the continuous concentration change method. Meanwhile, these findings of the hydrated $\mathrm{Pb}$ (II) of $\mathrm{PbOH}\left(\mathrm{H}_{2} \mathrm{O}\right)_{6}$ and the $\mathrm{Pb}$ (II)-BHA complex, as shown in Figure 5(b), suggested that the hydration shell of $\mathrm{Pb}$ (II) may be destroyed due to its coordination reaction with BHA.

The ESI-MS results have validated the existence of the $\mathrm{Pb}(\mathrm{II})$ complex with one and two BHA as ligands. The experimental approaches are not sufficient, however, to provide exact structures or properties at the microscopic scale; thus, the structures of $\mathrm{Pb}$ (II)-BHA complexes, have been further explored by using first-principle DFT calculations at high accuracy, including the solvation effects.

\subsection{Theoretical prediction}

3.2.1. Prediction of stable $\mathrm{BHA}$ isomers and $\mathrm{Pb}(\mathrm{II})-\mathrm{BHA}$ complexes 
(a)

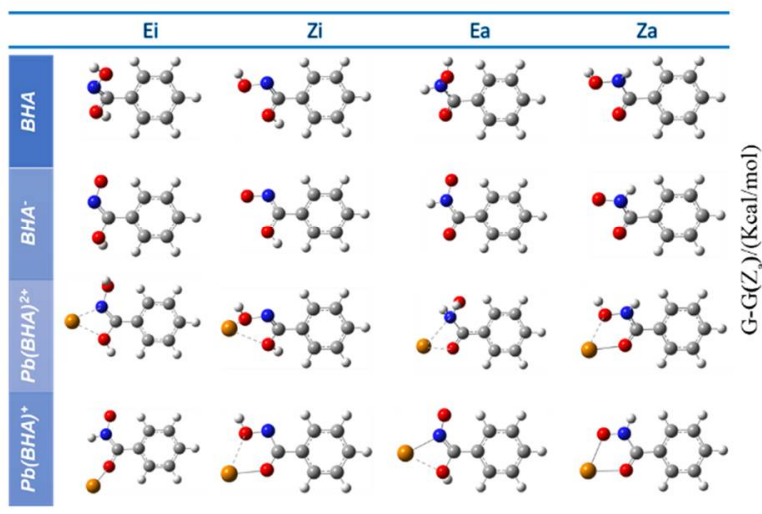

(b)

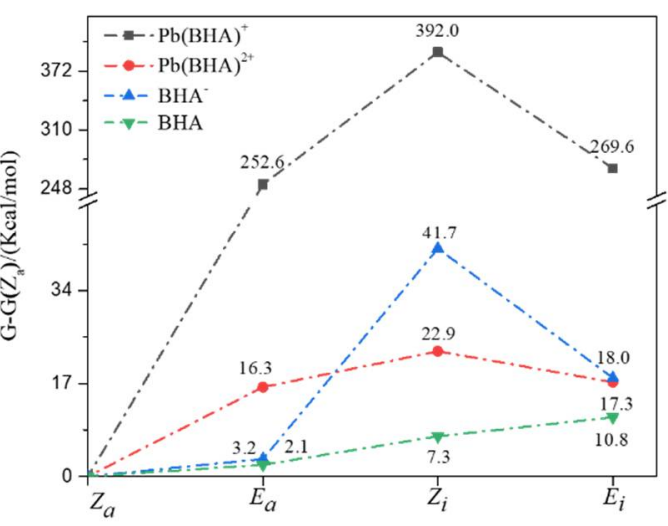

Figure 5. (a) Optimized structures of $\mathrm{BHA}, \mathrm{BHA}^{-}, \mathrm{Pb}(\mathrm{BHA})^{2+}$, and $\mathrm{Pb}(\mathrm{BHA})^{+}$. (b) Comparison of Gibbs free energy of $\mathrm{BHA}, \mathrm{BHA}^{-}, \mathrm{Pb}(\mathrm{BHA})^{2+}$, and $\mathrm{Pb}(\mathrm{BHA})^{+}$isomers with the Gibbs free energy of $\mathrm{Za}$ type as zero point. Spheres for $\mathrm{Pb}, \mathrm{C}, \mathrm{H}, \mathrm{O}$, and $\mathrm{N}$ atoms are colored in orange, gray, white, red, and blue, respectively.

All optimized BHA and BHA- (the anion of the BHA molecule with the dissociation of the proton) structures and their complexes with the $\mathrm{Pb}(\mathrm{II})$ ion are shown in the first two rows in Figure 5(a) at a B3LYP/aug-cc-pVDZ theoretical level. These optimized structures are divided into four categories called Ei, Zi, Ea and Za. From the calculation results as shown in Figure 5(b), it is clear that the corresponding $\mathrm{Za}$ type is most stable configuration for $\mathrm{BHA}, \mathrm{BHA}-\mathrm{Pb}(\mathrm{BHA})^{2+}$, and $\mathrm{Pb}(\mathrm{BHA})^{+}$. The interesting finding is that $\mathrm{BHA}$ prefers to coordinate with $\mathrm{Pb}(\mathrm{II})$ to form a "Pb-O-C-N-O" fivemembered ring, not a "Pb-O-C-N" four-membered ring, which is consistent with the previous report [26].

Because Za-type BHA is the most stable structure, it has been adopted in the following calculations and discussions. To better understand the interaction of Pb-BHA with water molecules, the influence of water molecules on the studied system has been further investigated using the explicit water molecules.

\subsubsection{Single $\mathrm{Pb}-\mathrm{BHA}$ in aqueous solution}

(a) Add water molecules one by one
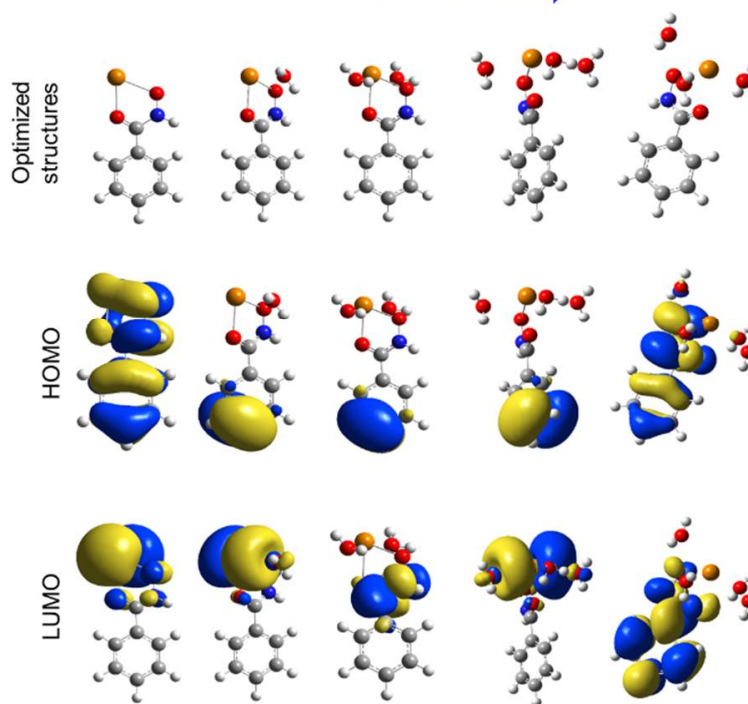

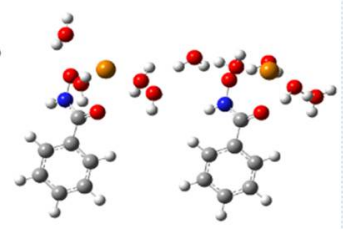

(b)

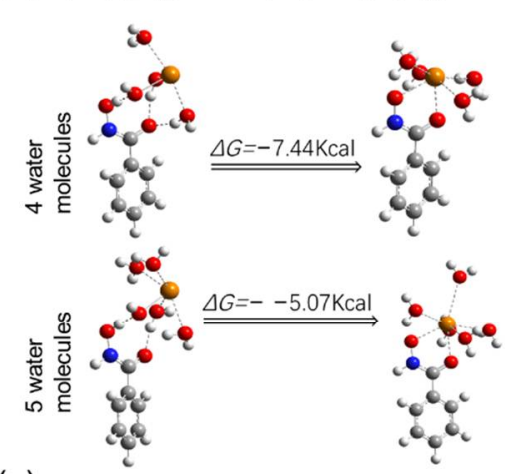

(c)
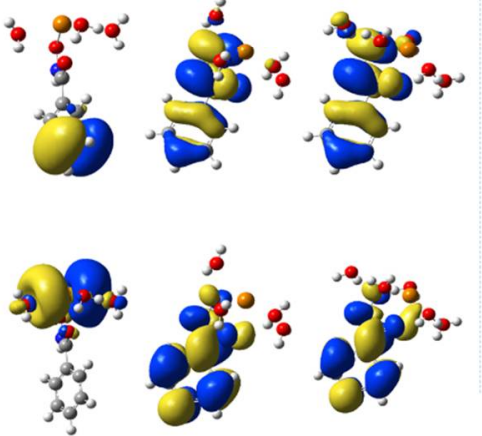

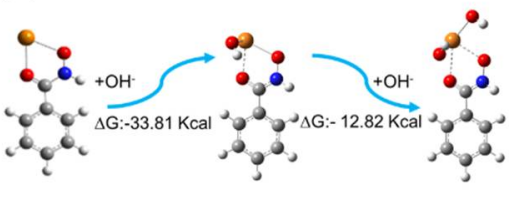

Figure 6. The optimized structure (top (a)) of hydrated $\mathrm{Pb}(\mathrm{BHA})^{+}$with the addition of water molecules one by one and the corresponding HOMO (middle (a)) and LUMO (bottom (a)); (b) Gibbs free energy difference between the hydrated $\mathrm{Pb}(\mathrm{BHA})^{+}$and hydrated $\mathrm{Pb}^{2+}+\mathrm{BHA}$ complex with four and five water 
molecules; (c) The hydroxylation of $\mathrm{Pb}(\mathrm{BHA})^{+}$. The contours have been computed at the PCM-B3LYP level of theory with a threshold of $0.001 \mathrm{au}$, and spheres for $\mathrm{Pb}, \mathrm{C}, \mathrm{H}, \mathrm{O}$, and $\mathrm{N}$ atoms are colored in orange, gray, white, red, and blue, respectively.

The hydration of lead-BHA complex with different coordination water molecules has been investigated to consider the real aqueous environment. As is shown in Figure 6a, water molecules were added one by one to coordinate with the $\mathrm{Pb}(\mathrm{BHA})^{+}$complex. This procedure can be described by Equation (4) and (5) below:

$$
\begin{gathered}
\mathrm{Pb}\left(\mathrm{H}_{2} \mathrm{O}\right)_{m}^{2+}+\mathrm{BHA}^{-} \leftrightarrow \mathrm{Pb}\left(\mathrm{H}_{2} \mathrm{O}\right)_{m}(\mathrm{BHA})^{+} \\
\mathrm{Pb}(\mathrm{BHA})^{+}\left(\mathrm{H}_{2} \mathrm{O}\right)_{m}+\mathrm{H}_{2} \mathrm{O} \leftrightarrow \mathrm{Pb}(\mathrm{BHA})^{+} \mathrm{H}_{2} \mathrm{O}_{(m+1)}
\end{gathered}
$$

where $\mathrm{m}(0 \rightarrow 4)$. Here, the hydrated lead(II) cation is a six folded complex in the first hydration shell, according to the previous report [50].

As shown in Figure 6a, the electronical density distribution of LUMO (bottom (a)) shifted from the lead ion to the BHA molecule, indicating the active site of the lead-BHA complex can be influenced by the coordinated water molecules. The increasing number of water molecules from 0 to 3 results in small differences in the electronical density distribution of LUMO and HOMO, which suggests the active site of $\mathrm{Pb}(\mathrm{BHA})^{+}$is stable. A fairly dispersed distribution of LUMO and $\mathrm{HOMO}$ on the whole complex has been observed, after adding more than 3 water molecules, which should be due to the influence of the surrounding water molecules.

Figure $\mathbf{6 b}$ shows the optimized structures of a BHA reacted with a hydrated lead(II) ion (left of Figure $\mathbf{6 b}$, denoted as $\left[\mathrm{Pb}\left(\mathrm{H}_{2} \mathrm{O}\right)_{\mathrm{m}}\right] \mathrm{BHA}$ ) and the hydration structure of $\mathrm{Pb}(\mathrm{BHA})^{+}$(right of Figure $6 \mathbf{b}$, denoted as $\left.(\mathrm{Pb}-\mathrm{BHA})\left(\mathrm{H}_{2} \mathrm{O}\right) \mathrm{m}\right)$ with four $(\mathrm{m}=4)$ and five $(\mathrm{m}=5)$ water molecules, respectively. The Gibbs free energy differences between $\left[\mathrm{Pb}\left(\mathrm{H}_{2} \mathrm{O}\right)_{\mathrm{m}}\right] \mathrm{BHA}$ and $(\mathrm{Pb}-\mathrm{BHA})\left(\mathrm{H}_{2} \mathrm{O}\right)_{\mathrm{m}}$ are $-7.44 \mathrm{Kcal} / \mathrm{mol}$ and $-5.07 \mathrm{Kcal} / \mathrm{mol}$ with respect to four $(\mathrm{m}=4)$ and five $(\mathrm{m}=5)$ water molecules, respectively. These calculated results show that $(\mathrm{Pb}-\mathrm{BHA})\left(\mathrm{H}_{2} \mathrm{O}\right)_{\mathrm{m}}$ is more favorable in thermodynamics.

As is tabulated in Table 1, all the Gibbs free energy differences of the coordination reactions of $(\mathrm{Pb}-\mathrm{BHA})^{+}\left(\mathrm{H}_{2} \mathrm{O}\right)_{\mathrm{m}}(\mathrm{m}>0)$ with another water molecule shown are positive, although all the Gibbs free energy changes of the coordination reactions of $\mathrm{Pb}^{2+}$ with water molecule are negative. This indicates that $\mathrm{Pb}^{2+}$ prefers to coordinate with more than 5 water molecules, but ( $\mathrm{Pb}-\mathrm{BHA}$ )- will not like to coordinate with more than two water molecules $(\Delta \mathrm{G}>10 \mathrm{Kcal} / \mathrm{mol}$ for the third water molecule), and in the hydration configurations of $(\mathrm{Pb}-\mathrm{BHA})\left(\mathrm{H}_{2} \mathrm{O}\right) \mathrm{m},(\mathrm{Pb}-\mathrm{BHA})^{-}$and $(\mathrm{Pb}-\mathrm{BHA})-\left(\mathrm{H}_{2} \mathrm{O}\right)$ should be the dominate species. These findings are consistent with the ESI-MS spectra.

On the other hand, with the addition of the coordinated water molecules, the average bond length of $\mathrm{Pb}-\mathrm{O}$ in both hydration systems of $(\mathrm{Pb}-\mathrm{BHA})^{+}\left(\mathrm{H}_{2} \mathrm{O}\right)_{m}$ and $\mathrm{Pb}\left(\mathrm{H}_{2} \mathrm{O}\right)_{m^{2+}}$ increased. The bond length of $\mathrm{Pb}-\mathrm{O}$ in $(\mathrm{Pb}-\mathrm{BHA})+\left(\mathrm{H}_{2} \mathrm{O}\right)$ is $2.53 \AA$, which is similar to the mean bond length of $\mathrm{Pb}-\mathrm{O}$ in $\mathrm{Pb}\left(\mathrm{H}_{2} \mathrm{O}\right)_{5}(2.55 \AA)$. In the structure chemistry, the basic idea is that the longer bond length, the less stable the corresponding complex. Thus, the changes of mean bond length of $\mathrm{Pb}-\mathrm{O}$ in $(\mathrm{Pb}-$ $\mathrm{BHA})^{+}\left(\mathrm{H}_{2} \mathrm{O}\right)_{m}$ and $\mathrm{Pb}\left(\mathrm{H}_{2} \mathrm{O}\right)_{m^{2+}}$ also confirmed that $(\mathrm{Pb}-\mathrm{BHA})+\left(\mathrm{H}_{2} \mathrm{O}\right)_{m}$ are less stable than $(\mathrm{Pb}-\mathrm{BHA})^{+}$and $\mathrm{Pb}\left(\mathrm{H}_{2} \mathrm{O}\right)_{m^{2+}}$.

In addition, the scheelite flotation [16] are usually performed at the alkaline $\mathrm{pH}$, hydroxyl ion $\left(\mathrm{OH}^{-}\right)$are a key component in the pulp. Thus, the coordination reactions of $\mathrm{Pb}(\mathrm{BHA})^{+}$with $\mathrm{OH}^{-}$were also investigated in this work. Herein, the coordination of the $\mathrm{Pb}(\mathrm{BHA})^{+}$with $\mathrm{OH}^{-}$has been simulated in a stepwise order as shown in Figure 6c. The reaction site has been chosen according to the LUMO of $\mathrm{Pb}(\mathrm{BHA})^{+}$. The optimized structures of $\mathrm{Pb}(\mathrm{BHA})(\mathrm{OH})$ and $\mathrm{Pb}(\mathrm{BHA})(\mathrm{OH})_{2}^{-}$and the reaction Gibbs free energies changes $(\Delta \mathrm{G})$ are also given in Figure $6 \mathrm{c}$. The coordination binding reaction of $\mathrm{Pb}(\mathrm{BHA})^{+}$ with the first hydroxyl and the second hydroxyl are $-33.81 \mathrm{Kcal} / \mathrm{mol}$ and $-12.82 \mathrm{Kcal} / \mathrm{mol}$, respectively. This result suggests that the coordination reaction of hydroxyl with the $\mathrm{Pb}(\mathrm{BHA})^{+}$are thermodynamically favorable. At a natural $\mathrm{pH}$ of 4.4 , both $\mathrm{Pb}^{2+}$ and $\mathrm{BHA}^{-}$should be the major reactants involved in the coordination reaction. At a real flotation plant, however, a higher $\mathrm{pH}$ value 
close to 9 is used. At such $\mathrm{pH}$, both $\mathrm{Pb}(\mathrm{BHA})(\mathrm{OH})$ and $\mathrm{Pb}(\mathrm{BHA})(\mathrm{OH})_{2}^{-}$could exist in the flotation solution. These results are in good accordance with experimental $\mathrm{m} / \mathrm{z}$ value of 383 and 423 in ESI-MS spectra, which refer to $\left(\mathrm{Pb}(\mathrm{BHA})(\mathrm{OH})+\mathrm{Na}^{+}\right)$and the $\left(\mathrm{Pb}(\mathrm{BHA})(\mathrm{OH})_{2}+2 \mathrm{Na}^{+}\right)$species in Figure 4, respectively.

Table 1. The changes in the reaction Gibbs free energy $(\Delta \mathrm{G})$ and the difference of $\mathrm{Pb}-\mathrm{O}$ mean distance in the hydration system with coordination number $(\mathrm{CN}) \mathrm{m}$ of water molecules varied from 1 to 5 .

\begin{tabular}{ccccc}
\hline CN of water & \multicolumn{2}{c}{$\Delta \mathbf{G} /(\mathbf{K c a l} / \mathbf{m o l})$} & \multicolumn{2}{c}{ Pb-O Mean distance ( ) } \\
\cline { 2 - 4 } molecules(m) & $(P b-B H A)^{+}\left(\mathrm{H}_{2} \mathrm{O}\right)_{m}$ & $P b\left(H_{2} \mathrm{O}\right)_{m}{ }^{2+}$ & $(P b-B H A)^{+}\left(H_{2} O\right)_{m}$ & $P b\left(H_{2} O\right)_{m}{ }^{2+}$ \\
1 & 1.41 & -50.48 & 2.53 & 2.34 \\
2 & 1.38 & -36.75 & 2.64 & 2.38 \\
3 & 7.40 & -27.34 & 2.69 & 2.42 \\
4 & 4.64 & -17.65 & 2.77 & 2.49 \\
5 & 8.35 & -14.56 & 2.83 & 2.55 \\
\hline
\end{tabular}

Consistently positive $\Delta \mathrm{G}$ of the coordination reactions of $(\mathrm{Pb}-\mathrm{BHA})^{+}\left(\mathrm{H}_{2} \mathrm{O}\right) \mathrm{m}(\mathrm{m}>1)$ with another water molecule should be ascribed to the result of the stronger coordination of $\mathrm{BHA}^{-}$with $\mathrm{Pb}^{2+}(\Delta \mathrm{G}$ is $-356.55 \mathrm{kcal} / \mathrm{mol}$ as listed in Table 1). The coordination involving charge transfer from the ligand $\mathrm{BHA}$ - to the metal ion $\mathrm{Pb}^{2+}$ makes the properties and electronic structure of $\mathrm{Pb}$-BHA less active than the independent lead(II) ion. The results agree well with the transformation in Figure $\mathbf{6 b}$, where the bonded $\mathrm{BHA}$ is strong enough to protect the $\mathrm{Pb}^{2+}$ from the influence of surrounding water molecules.

Based on these results and discussions (the BHA- can coordinate with the $\mathrm{Pb}$ (II) smoothly), the following work has been conducted under the implicit model rather than explicit water molecules.

3.2.3. High coordination complexes

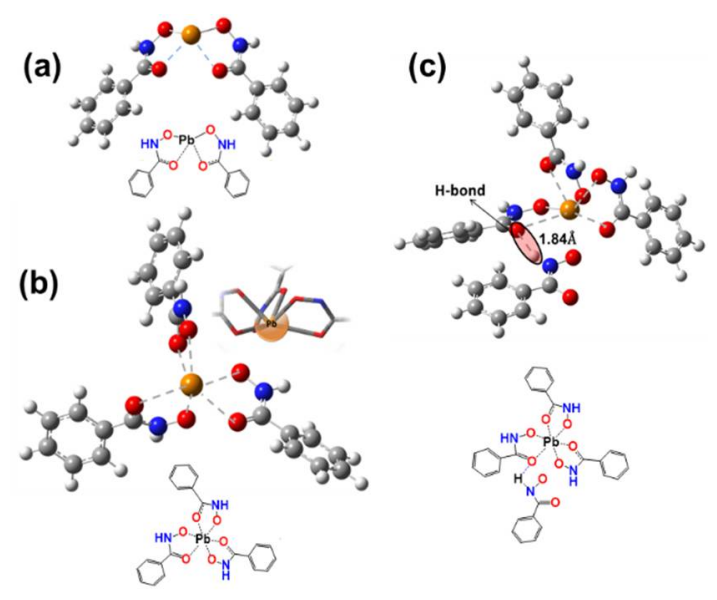

Figure 7. Optimized structures of $\mathrm{Pb}(\mathrm{II})$-BHA with coordination numbers (CN) of 2 (a), 3 (b), and 4 (c). Spheres for $\mathrm{Pb}, \mathrm{C}, \mathrm{H}, \mathrm{O}$, and $\mathrm{N}$ atoms are colored in orange, gray, white, red, and blue, respectively.

Table 2. The changes in Gibbs free energy $(\Delta \mathrm{G})$ and $\mathrm{Pb}-\mathrm{O}$ mean distance in $\mathrm{Pb}(\mathrm{II})$ - $\mathrm{BHA}$ complexes with $\mathrm{CN}$ of $\mathrm{BHA}$ ligands ranging from 1 to 3.

\begin{tabular}{ccccc}
\hline $\mathbf{C N}$ & Reaction & $\Delta$ G(Kcal/mol) & Pb-O ( ) & $\varepsilon_{\text {gap }}(\mathbf{e V})$ \\
\hline 1 & $\mathrm{~Pb}^{2+}+\mathrm{BHA}^{-}$ & -356.55 & 2.26 & 4.17 \\
2 & $\mathrm{~Pb}\left(\mathrm{BHA}^{+}+\mathrm{BHA}^{-}\right.$ & -27.20 & 2.40 & 4.50 \\
3 & $\mathrm{~Pb}\left(\mathrm{BHA}_{2}+\mathrm{BHA}^{-}\right.$ & +0.03 & 2.58 & 4.17 \\
\hline
\end{tabular}


In thermodynamics, the isomer with the lowest Gibbs free energy $(G)$ could be the most stable and most efficient isomer; $\mathrm{Za}$ type structures should be the optimal configurations and the dominant components according to the Gibbs free energies shown in Figure 5(b), which is consistent with the results obtained by Begoña et al. [32]. The Za type structure as the ligand has been used for the subsequent calculations. The initial $\mathrm{Pb}$ (II)-BHA coordination complexes are modeled with the $\mathrm{Pb}$ (II) ion as the central metal ion, based on the stepwise mechanism in Equation 2. To obtain the possible high coordination compounds, we increased the number of BHA ligand to 4 .

As shown in Figure 7, all $\mathrm{Pb}$ (II)-BHA coordination complexes possess hemidirected geometry (in such configuration, BHA ligands occupy merely half of the space surrounding the $\mathrm{Pb}$ (II) atom) $[7,50,60]$. As shown in Table 2, the reaction between the BHA with the $\mathrm{Pb}$ (II) (Figure 7(a)) corresponds to a total reaction free energy change of $-356.55 \mathrm{Kcal} / \mathrm{mol}$, indicating the Pb-BHA- is a fairly favorable specie in thermodynamics. For the second BHA- ligand (Figure $\mathbf{7}(\mathbf{b})$ ), the total reaction free energy change is $-27.20 \mathrm{Kcal} / \mathrm{mol}$, excluding the formation free energy of $\mathrm{Pb}(\mathrm{BHA})^{+}$. The reaction energy ($356.55 \mathrm{Kcal} / \mathrm{mol})$ of $\mathrm{BHA}^{-}$with $\mathrm{Pb}^{2+}$ is much higher than that of water molecules with $\mathrm{Pb}(-50.48$ $\mathrm{Kcal} / \mathrm{mol})$, indicating the coordination reaction of $\mathrm{BHA}^{-}$with $\mathrm{Pb}^{2+}$ will be more efficient than that of $\mathrm{H}_{2} \mathrm{O}$ with $\mathrm{Pb}^{2+}$.

Thereafter, the coordination reaction of the third BHA- produces a positive change in Gibbs free energy of $0.03 \mathrm{Kcal} / \mathrm{mol}$, implying that the binding of the third water molecule with the former $\mathrm{Pb}(\mathrm{BHA})_{2}$ is not favorable in thermodynamics. Moreover, as is shown in Figure 7(c), when $\mathrm{CN}$ reaches 4 , the intramolecular aggregation occurred by a hydrogen bonding interaction $(\mathrm{N}-\mathrm{H}$...O) between the added BHA- and another adjoining BHA; with hydrogen bond length of $1.84 \AA$ [ [26,61]. A higher $\mathrm{CN}$ than 3 should not be stable, but a $\mathrm{Pb}$ (II)-BHA complex with 3 or more BHA ligands may appear due to the intermolecular interactions, including the Van der Waals' force, H-bonding interaction.

3.2.4. Frontier molecular orbital analysis

(a)

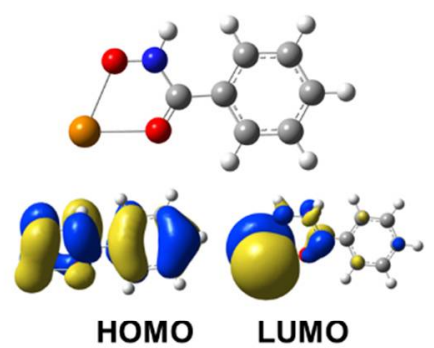

(b)

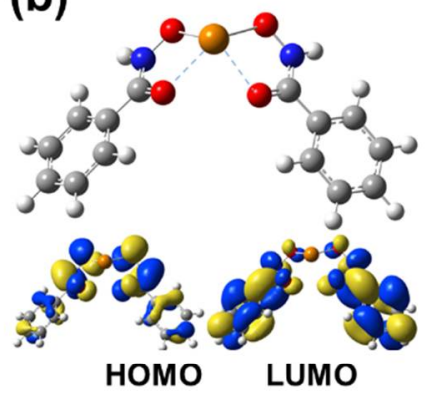

(c)

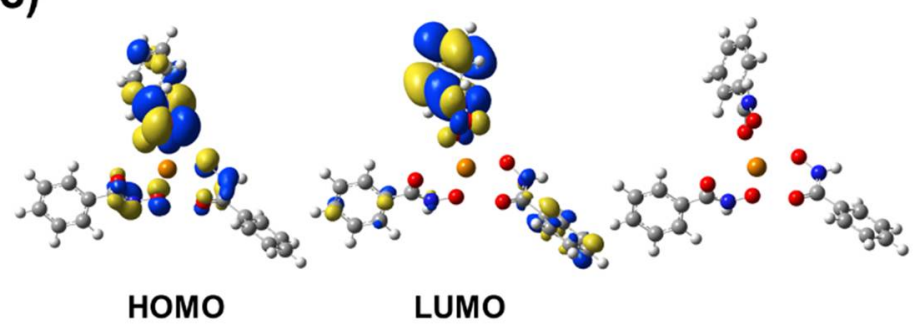

Figure 8. The frontier molecular orbitals (HOMO and LUMO) of $\mathrm{Pb}$ (II)-BHA complexes with 1 (a), 2 (b), and 3 (c) BHA ligands. The orbitals are generated at the B3LYP/ aug-cc-pVDZ theory level with a threshold of $0.001 \mathrm{au}$, and the solvation effect is included with PCM model. Spheres for Pb, C, H, O, and $\mathrm{N}$ atoms are colored in orange, gray, white, red, and blue, respectively. 
Table 3. The contribution of the $\mathrm{Pb}$ atom to frontier molecular orbitals (HOMO+1, HOMO, LUMO, and LUMO-1) based on the NAO[62] method .

\begin{tabular}{ccccc}
\hline \multirow{2}{*}{$\mathbf{P b}-\mathbf{B H A}$} & \multicolumn{3}{c}{ Orbital composition assigned to $\mathbf{P b}$ atom/\% } \\
\cline { 2 - 5 } & HOMO-1 & HOMO & LUMO & LUMO+1 \\
$\mathrm{Pb}(\mathrm{BHA})^{+}$ & 0.03 & 3.55 & 91.93 & 77.54 \\
$\mathrm{~Pb}(\mathrm{BHA})_{2}$ & 1.14 & 1.28 & 1.14 & 0.02 \\
$\mathrm{~Pb}(\mathrm{BHA})_{3}^{-}$ & 1.01 & 0.75 & 0.13 & 0.00 \\
\hline
\end{tabular}

In Figure 9, the ligands of $\mathrm{Pb}(\mathrm{BHA})_{2}$ (b) and $\mathrm{Pb}(\mathrm{BHA})_{3}^{-}$(c) occupied just half of the space surrounding the $\mathrm{Pb}(\mathrm{II})$ ions. $\mathrm{Pb}(\mathrm{BHA})_{2}$ and $\mathrm{Pb}(\mathrm{BHA})_{3}$ adopted the hemidirected $\mathrm{Pb}$ (II)- $\mathrm{BHA}$ structures due to the lone pair electron contributed by BHA ligands [50,63]. Additionally, the structure of BHA can form some dimer structures and even interact with themselves. The adjoining BHA may result in aggregation due to intermolecular interaction [32].

As is illustrated in Figure 8(a), the LUMO of $\mathrm{Pb}(\mathrm{BHA})^{+}$is mainly located at the $\mathrm{Pb}$ atom indicating that the $\mathrm{Pb}$ site of the $\mathrm{Pb}(\mathrm{BHA})^{+}$should be active in electrophilic reaction. The LUMO of $\mathrm{Pb}(\mathrm{BHA})_{2}$ in Figure $\mathbf{7 ( b )}$ and the $\left.\mathrm{Pb}(\mathrm{BHA})\right)_{3}^{-}$in Figure 8(c), however, spreads over the whole molecule, suggesting that the molecule is not active in electrophilic reaction. Becasue the $\mathrm{Pb}$ (II)-BHA is used as selective collector of oxide mineral, where the hydrated oxide mineral surface is an electron rich system, the $\mathrm{Pb}(\mathrm{BHA})^{+}$can be more actively absorb onto the surface than other species in the $\mathrm{Pb}$ (II)-BHA solution. Additionally, as shown in Table 3, the $\mathrm{Pb}$ atom contributes $91.93 \%$ to the LUMO, a rate much higher than that in other $\mathrm{Pb}$ (II)-BHA complexes, based on the NAO[62] method. These results have further verified that the $\mathrm{Pb}$ atom in $\mathrm{Pb}(\mathrm{BHA})^{+}$can be the active site to adsorb onto the oxide minerals surface. This is consistent with the reported results $[9,10,24,64]$.

\section{Conclusions}

In the present study, the micro-structures of lead(II)-benzohydroxamic acid coordination compounds in aqueous solution were investigated by Ultraviolet-visible (UV-Vis) spectroscopy and electrospray ionization-mass spectrometry (ESI-MS), as well as first-principles density functional theory (DFT) calculations.

Job plots considering two dosing strategies indicate that the $\mathrm{Pb}$ coordination compounds in solution may adopt the stoichiometry of $\mathrm{Pb}(\mathrm{BHA})^{+}$and $\mathrm{Pb}(\mathrm{BHA})_{2}$. UV-Vis results obtained by the equimolar continuous change method show that the $\mathrm{Pb}(\mathrm{BHA})^{+}$and the high coordination number compounds should be formed stepwise in aqueous solution. Thereafter, the ESI-MS spectra provide strong proofs that the $\mathrm{Pb}(\mathrm{BHA})^{+}$and $\mathrm{PbOH}(\mathrm{BHA})_{2}^{+}$should be the dominant species at the alkaline $\mathrm{pH}$ in solution; and the $\mathrm{Pb}(\mathrm{BHA})^{+}$should be the major component in aqueous solution at the natural $\mathrm{pH}$. Furthermore, DFT calculated results show that: the Za type BHA should be the major structure; the $\mathrm{Pb}(\mathrm{BHA})^{+}$can be stable in aqueous solution; and the formation of higher coordination number complexes are not favorable. Finally, the frontier molecular orbitals analyses show that the $\mathrm{Pb}$ atom of $\mathrm{Pb}(\mathrm{BHA})^{+}$is the largest contributor to the LUMO. This suggests that the $\mathrm{Pb}$ atom in the structure should be the active site for accepting nucleophile and can also be the active site to adsorb onto the surface of oxide minerals. These findings are meaningful to further illustrate the adsorption mechanism of $\mathrm{Pb}(\mathrm{II})$-BHA complexes in mineral processing.

Acknowledgments: The work was supported by Natural Science Foundation of China (No. 51704330); the Found of State Key Laboratory of Mineral Processing (No. BGRIMM-KJSKL-2017-13); Natural Science Foundation of China (NO. 51374247); the Startup Fund of Central South University for Young Teachers (502044001); The Innovation Program for Postgraduate Students of Central South University (No. 2018zzts802); the National 111 Project (No. B14034); Collaborative Innovation Center for Clean and Efficient Utilization of Strategic Metal Mineral Resources; Innovation Driven Plan of Central South University (No. 2015CX005); Key Laboratory of Hunan Province for Clean and Efficient Utilization of Strategic Calcium-containing Mineral 
Resources (No. 2018TP1002); and the National Science and Technology Support Project of China. This work was carried out in part using hardware and/or software provided by a Tianhe II supercomputer at the National Supercomputing Center in Guangzhou, and the High-Performance Computing Centers of Central South University and Nanjing University. ESI-MS measurements were conducted at the Modern Analysis and Testing Center of CSU.

\section{References}

1. Hou, G.L.; Chen, B.; Transue, W.J.; Yang, Z.; Grutzmacher, H.; Driess, M.; Cummins, C.C.; Borden, W.T.; Wang, X.B. Spectroscopic characterization, computational investigation, and comparisons of ecx- $(\mathrm{e}=$ as, p, and $\mathrm{n} ; \mathrm{x}=\mathrm{s}$ and o) anions. J Am Chem Soc 2017, 139, 8922-8930.

2. Kuta, J.; Clark, A.E. Trends in aqueous hydration across the $4 \mathrm{f}$ period assessed by reliable computational methods. Inorg Chem 2010, 49, 7808-7817.

3. Aguilo, E.; Moro, A.J.; Gavara, R.; Alfonso, I.; Perez, Y.; Zaccaria, F.; Guerra, C.F.; Malfois, M.; Baucells, C.; Ferrer, M., et al. Reversible self-assembly of water-soluble gold(i) complexes. Inorg Chem 2017.

4. Akturk, E.S.; Scappaticci, S.J.; Seals, R.N.; Marshak, M.P. Bulky beta-diketones enabling new lewis acidic ligand platforms. Inorg Chem 2017, 56, 11466-11469.

5. Bhatta, S.R.; Mondal, B.; Vijaykumar, G.; Thakur, A. Ict-isomerization-induced turn-on fluorescence probe with a large emission shift for mercury ion: Application in combinational molecular logic. Inorg Chem 2017, 56, 11577-11590.

6. Choi, K.M.; Kim, D.; Rungtaweevoranit, B.; Trickett, C.A.; Barmanbek, J.T.; Alshammari, A.S.; Yang, P.; Yaghi, O.M. Plasmon-enhanced photocatalytic $\operatorname{co}(2)$ conversion within metal-organic frameworks under visible light. J Am Chem Soc 2017, 139, 356-362.

7. Jalilehvand, F.; Sisombath, N.S.; Schell, A.C.; Facey, G.A. Lead(ii) complex formation with 1-cysteine in aqueous solution. Inorg Chem 2015, 54, 2160-2170.

8. $\quad$ Li, J.; Yu, X.; Xu, M.; Liu, W.; Sandraz, E.; Lan, H.; Wang, J.; Cohen, S.M. Metal-organic frameworks as micromotors with tunable engines and brakes. J Am Chem Soc 2017, 139, 611-614.

9. Han, H.; Hu, Y.; Sun, W.; Li, X.; Chen, K.; Zhu, Y.; Nguyen, A.V.; Tian, M.; Wang, L.; Yue, T., et al. Novel catalysis mechanisms of benzohydroxamic acid adsorption by lead ions and changes in the surface of scheelite particles. Minerals Engineering 2018, 119, 11-22.

10. Tian, M.; Hu, Y.; Sun, W.; Liu, R. Study on the mechanism and application of a novel collectorcomplexes in cassiterite flotation. Colloids and Surfaces A: Physicochemical and Engineering Aspects 2017, $522,635-641$.

11. Han, H.; Hu, Y.; Sun, W.; Li, X.; Cao, C.; Liu, R.; Yue, T.; Meng, X.; Guo, Y.; Wang, J., et al. Fatty acid flotation versus bha flotation of tungsten minerals and their performance in flotation practice. Int. J. Miner. Process. 2017, 159, 22-29.

12. Gao, Z.; Li, C.; Sun, W.; Hu, Y. Anisotropic surface properties of calcite: A consideration of surface broken bonds. Colloids and Surfaces A: Physicochemical and Engineering Aspects 2017, 520, 53-61.

13. Li, C.; Gao, Z. Effect of grinding media on the surface property and flotation behavior of scheelite particles. Powder Technol. 2017, 322.

14. Sun, L.; Hu, Y.-h.; Sun, W. Effect and mechanism of octanol in cassiterite flotation using benzohydroxamic acid as collector. Transactions of Nonferrous Metals Society of China 2016, 26, 3253-3257.

15. Gao, Z.Y.; Sun, W.; Hu, Y.H. New insights into the dodecylamine adsorption on scheelite and calcite: An adsorption model. Minerals Engineering 2015, 79, 54-61. 
16. Han, H.-S.; Liu, W.-L.; Hu, Y.-H.; Sun, W.; Li, X.-D. A novel flotation scheme: Selective flotation of tungsten minerals from calcium minerals using pb-bha complexes in shizhuyuan. Rare Metals 2017, 36, 533-540.

17. Hu, Y.; Qiu, G.; Miller, J.D. Hydrodynamic interactions between particles in aggregation and flotation. Int. J. Miner. Process. 2003, 70, 157-170.

18. Zhao, G.; Wang, S.; Zhong, H. Study on the activation of scheelite and wolframite by lead nitrate. Minerals 2015, 5, 247-258.

19. Filippova, I.V.; Filippov, L.O.; Duverger, A.; Severov, V.V. Synergetic effect of a mixture of anionic and nonionic reagents: Ca mineral contrast separation by flotation at neutral ph. Minerals Engineering 2014, 66-68, 135-144.

20. Deng, L.; Zhao, G.; Zhong, H.; Wang, S.; Liu, G. Investigation on the selectivity of n-((hydroxyamino)alkyl) alkylamide surfactants for scheelite/calcite flotation separation. Journal of Industrial and Engineering Chemistry 2016, 33, 131-141.

21. Chen, Z.; Ren, Z.; Gao, H.; Lu, J.; Jin, J.; Min, F. The effects of calcium ions on the flotation of sillimanite using dodecylammonium chloride. Minerals 2017, 7, 28.

22. Materna, K.L.; Crabtree, R.H.; Brudvig, G.W. Anchoring groups for photocatalytic water oxidation on metal oxide surfaces. Chemical Society reviews 2017, 46, 6099-6110.

23. Gao, Y.; Gao, Z.; Sun, W.; Yin, Z.; Wang, J.; Hu, Y. Adsorption of a novel reagent scheme on scheelite and calcite causing an effective flotation separation. J Colloid Interface Sci 2017, 512, 39-46.

24. Tian, M.; Gao, Z.; Han, H.; Sun, W.; Hu, Y. Improved flotation separation of cassiterite from calcite using a mixture of lead (ii) ion/benzohydroxamic acid as collector and carboxymethyl cellulose as depressant. Minerals Engineering 2017, 113, 68-70.

25. Schraml, J. Derivatives of hydroxamic acids. Applied Organometallic Chemistry 2000, 14, 604-610.

26. Codd, R. Traversing the coordination chemistry and chemical biology of hydroxamic acids. Coordination Chemistry Reviews 2008, 252, 1387-1408.

27. Flipo, M.; Charton, J.; Hocine, A.; Dassonneville, S.; Deprez, B.; Deprez-Poulain, R. Hydroxamates: Relationships between structure and plasma stability. Journal of medicinal chemistry 2009, 52, 6790-6802.

28. Al-Saadi, A.A. Conformational analysis and vibrational assignments of benzohydroxamic acid and benzohydrazide. Journal of Molecular Structure 2012, 1023, 115-122.

29. Lynch, A.J.; Watt, J.S.; Fich, J.A.; Harbort, G.J. History of flotation technology. 2007, 65-91.

30. Lei, X.L.; Pan, B.C. The geometries and proton transfer of hydrated divalent lead ion clusters $[\mathrm{pb}(\mathrm{h} 2 \mathrm{o}) \mathrm{n}] 2+(\mathrm{n}=1-17)$. Journal of Theoretical \& Computational Chemistry 2012, 11, 1149-1164.

31. Wander, M.C.; Rustad, J.R.; Casey, W.H. Influence of explicit hydration waters in calculating the hydrolysis constants for geochemically relevant metals. Journal of Physical Chemistry A 2010, 114, 1917.

32. García, B.; Ibeas, S.; Leal, J.M.; Secco, F.; Venturini, M.; Senent, M.L.; Niño, A.; Muñoz, C. Conformations, protonation sites, and metal complexation of benzohydroxamic acid. A theoretical and experimental study. Inorganic Chemistry 2005, 44, 2908.

33. Adiguzel, E.; Yilmaz, F.; Emirik, M.; Ozil, M. Synthesis and characterization of two new hydroxamic acids derivatives and their metal complexes. An investigation on the keto/enol, e/z and hydroxamate/hydroximate forms. Journal of Molecular Structure 2017, 1127, 403-412.

34. Caudle, M.T.; Crumbliss, A.L. Dissociation kinetics of (n-methylacetohydroxamato)iron(iii) complexes: A model for probing electronic and structural effects in the dissociation of siderophore complexes. Computational Optimization \& Applications 2009, 43, 353-377. 
35. O'Brien, E.C.; Farkas, E.; Gil, M.J.; Fitzgerald, D.; Castineras, A.; Nolan, K.B. Metal complexes of salicylhydroxamic acid (h2sha), anthranilic hydroxamic acid and benzohydroxamic acid. Crystal and molecular structure of $[\mathrm{cu}(\mathrm{phen}) 2(\mathrm{cl})] \mathrm{cl} \times \mathrm{h} 2 \mathrm{sha}$, a model for a peroxidase-inhibitor complex. Journal of Inorganic Biochemistry 2000, 79, 47-51.

36. Bodwin, J.J.; Cutland, A.D.; Malkani, R.G.; Pecoraro, V.L. Cheminform abstract: The development of chiral metallacrowns into anion recognition agents and porous materials. Coordination Chemistry Reviews 2001, s 216-217, 489-512.

37. Pereira, C.F.; Howarth, A.J.; Vermeulen, N.A.; Almeida Paz, F.A.; Tomé, J.P.C.; Hupp, J.T.; Farha, O.K. Towards hydroxamic acid linked zirconium metal-organic frameworks. Mater. Chem. Front. 2017, 1, 1194-1199.

38. Fukui, K.; Yonezawa, T.; Nagata, C. Theory of substitution in conjugated molecules. Bull.chem.soc.jpn 1954, 27, 423-427.

39. Glendening, E.D.; Landis, C.R.; Weinhold, F. Natural bond orbital methods. Wiley Interdisciplinary Reviews: Computational Molecular Science 2012, 2, 1-42.

40. Perera, W.N.; Glenn Hefter, A.; Sipos, P.M. An investigation of the lead(ii)-hydroxide system. Inorganic Chemistry 2001, 40, 3974-3978.

41. Renny, J.S.; Tomasevich, L.L.; Tallmadge, E.H.; Collum, D.B. Method of continuous variations: Applications of job plots to the study of molecular associations in organometallic chemistry. Angewandte Chemie 2013, 52, 11998-12013.

42. Frisch, M.; Trucks, G.; Schlegel, H.B.; Scuseria, G.; Robb, M.; Cheeseman, J.; Scalmani, G.; Barone, V.; Mennucci, B.; Petersson, G. Gaussian 09, revision d. 01. Gaussian, Inc., Wallingford CT: 2009.

43. Becke, A.D. Becke's three parameter hybrid method using the lyp correlation functional. J. Chem. Phys 1993, 98, 5648-5652.

44. Yu, H.S.; Li, S.L.; Truhlar, D.G. Perspective: Kohn-sham density functional theory descending a staircase. J Chem Phys 2016, 145, 130901.

45. Ho, J.; Ertem, M.Z. Calculating free energy changes in continuum solvation models. The journal of physical chemistry. B 2016, 120, 1319-1329.

46. Feller, D. The role of databases in support of computational chemistry calculations. Journal of Computational Chemistry 1996, 17, 1571-1586.

47. Malekghassemi, M. An exploration of molecular mechanics and quantum chemical methods.

48. Lei, X.L.; Pan, B.C. The geometries and proton transfer of hydrated divalent lead ion clusters [pb(h2o)n]2+(n = 1-17). Journal of Theoretical and Computational Chemistry 2012, 11, 1149-1164.

49. Lee, Y.S.; Ermler, W.C.; Pitzer, K.S. Ab initio effective core potentials including relativistic effects. V. Scf calculations with $\omega-\omega$ coupling including results for au2+, th, pbs, and pbse. The Journal of Chemical Physics 1980, 73, 360-366.

50. Wander, M.C.F.; Clark, A.E. Hydration properties of aqueous pb(ii) ion. Inorganic Chemistry 2008, 47, 8233.

51. Ochterski, J.W. Vibrational analysis in gaussian. help@ gaussian.com 1999.

52. Arora, R.; Issar, U.; Kakkar, R. Theoretical study of the molecular structure and intramolecular proton transfer in benzohydroxamic acid. Computational and Theoretical Chemistry 2017, 1105, 18-26.

53. Steinberg, G.M.; Swidler, R. The benzohydroxamate anion. Journal of Organic Chemistry 1965, 30.

54. Ochterski, J.W. Thermochemistry in gaussian. Gaussian Inc 2000.

55. Dennington, R.; Keith, T.; Millam, J. Gaussview, version 5. Semichem Inc., Shawnee Mission, KS 2009. 
56. Lu, T.; Chen, F. Multiwfn: A multifunctional wavefunction analyzer. Journal of Computational Chemistry 2012, 33, 580-592.

57. Mikhail Rekharsky; Yoshihisa Inoue, +; Suzanne Tobey; Axel Metzger, A.; Eric Anslyn. Ion-pairing molecular recognition in water: Aggregation at low concentrations that is entropy-driven. Journal of the American Chemical Society 2002, 124, 14959-14967.

58. Bruneau, E. Quantitative analysis of continuous-variation plots with a comparison of several methods: Spectrophotometric study of organic and inorganic 1:1 stoichiometry complexes. Journal of Chemical Education 1992, 69, 833.

59. Wise, W.M.; Brandt, W.W. Spectrophotometric determination of vandium(v) with benzohydroxamic acid and 1-hexanol. Anal. Chem. 1955, 27, 1392-1395.

60. Leon-Pimentel, C.I.; Amaro-Estrada, J.I.; Saint-Martin, H.; Ramirez-Solis, A. Born-oppenheimer molecular dynamics studies of pb(ii) micro hydrated gas phase clusters. J Chem Phys 2017, 146, 084307.

61. Azizi, A.; Ebrahimi, A. The $x-\cdots$ benzohydrazide complexes: The interplay between anion- $\pi$ and h-bond interactions. Structural Chemistry 2016, 28, 687-695.

62. Lu, T.; Chen, F. Calculation of molecular orbital composition. Acta Chimica Sinica 2011, 69, 2393-2406.

63. Moncomble, A.; Cornard, J.P.; Meyer, M. A quantum chemistry evaluation of the stereochemical activity of the lone pair in pbii complexes with sequestering ligands. Journal of molecular modeling 2017, 23,24 .

64. Wei, Z.; Hu, Y.; Han, H.; Sun, W.; Wang, R.; Wang, J. Selective flotation of scheelite from calcite using al-na2sio3 polymer as depressant and pb-bha complexes as collector. Minerals Engineering 2018, 120, 2934. 